\title{
ACADEMIC PROCRASTINATION AND ANXIETY AMONG STUDENTS
}

\author{
Jelena Saplavska ${ }^{1}$, Aleksandra Jerkunkova ${ }^{2}$ \\ ${ }^{1}$ Baltic International Academy, Latvia; ${ }^{2}$ Latvia University of Life Sciences and Technologies, Latvia \\ lena.sap1@inbox.lv, lelllle@inbox.lv
}

\begin{abstract}
Procrastination is a complex, psychologically heterogeneous phenomenon that includes behavioural, emotional and cognitive components. The main areas of manifestation of procrastination are professional and educational activities. Academic procrastination implies a delay in the fulfilment of educational assignments and is associated with undeveloped learning skills, lack of organization, forgetfulness, and behavioural rigidity. The consequence of this behaviour in most cases is the decrease in academic achievement, negative emotional experiences related to own failure, anxiety, and dissatisfaction with the results. Procrastination negatively affects the psychological well-being of students; therefore, this phenomenon is of special interest in the context of future specialists training. Available data demonstrate that $46 \%$ to $95 \%$ of secondary school pupils and higher educational institution students consider themselves to be procrastinators requiring professional psychological help. The study aimed to reveal the links between academic procrastination and anxiety among students. The participants in this study were 60 second year students of the Latvia University of Life Sciences and Technologies, Faculty of Engineering, aged 20-27. The Procrastination Scale was used to measure academic procrastination; State-Trait Anxiety Inventory (Form Y) was implemented to investigate anxiety. The study revealed that $48 \%$ of the participants demonstrated a high level of academic procrastination, $27 \%$ - medium and $25 \%$ - low. The link between academic procrastination and situational and personal anxiety was revealed. The obtained data showed that with the situational and personal anxiety increase, the level of academic procrastination also increases. The development of recommendations, balanced workload distribution and an encouraging learning environment will reduce the level of academic procrastination among students.
\end{abstract}

Keywords: academic procrastination, personal and situational anxiety.

\section{Introduction}

The life of a modern person abounds with various tasks and assignments, which implementation is associated with certain deadlines for delivery and clear time limits available for execution of those tasks. Whilst acknowledging the time frames, a person can plan his or her time, effort and resources, however, in a situation of constant tension and multitasking, it often happens that there is a need or a desire to postpone the execution of some tasks for later. The phenomenon of postponing tasks for later is described by term "procrastination". There is no single generally accepted definition of procrastination. Some authors [1-3] believe that procrastination is a voluntary, irrational postponement of the intended actions, despite the fact that this entails a negative effect on the individual. The opposite view is held by other researchers [4], arguing that not all delays lead to negative consequences. Many people, even though beginning to work at the last minute, can finish the task on time as they generate more creative ideas under the pressure of a limited time. In [5], the authors characterize procrastination as a striving for a strong feeling of a thrill, which appears when the task is accomplished in the shortest possible due time. In the meta-analytical review [6] an attempt was made to combine the main distinctive features of procrastination. Firstly, all of them are united by the fact of postponing - procrastination is always related to delay, non-completion of tasks. Secondly, the postponing is always related to tasks always tied to certain deadlines. Thirdly, procrastination always leads to negative consequences, accompanied by negative feelings, guilt, anxiety, etc.

As a psychological phenomenon, procrastination is a complex that includes behavioural $[5 ; 7-8]$, emotional, cognitive [9-12] and subconscious [13] components. The behavioural component is seen as a set mechanism of human behaviour. Within the cognitive approach, can be distinguished irrational beliefs, low self-esteem, inability to make decisions independently; emotionally loaded anxiety, emotional overload, fear of failure and neuroticism. The basis of the subconscious component is a defensive mechanism, which can be activated upon increased anxiety, when the situation of a task accomplishing is perceived as threatening and dangerous.

The authors [14] distinguish several types of procrastination: domestic (postponing routine household chores); procrastination in decision-making, including minor ones; neurotic - postponing substantial decisions (choosing a profession, creating a family); compulsive, where two types of procrastination are combined - behavioural and in decision-making; academic - postponing the accomplishment of study assignments, preparation for exams, etc. 
Academic procrastination contains two main processes [15]: an inclination to always or almost always postpone the fulfilment of study assignments and always or almost always experience anxiety related to this postponement. In the article [16], it is noted that one of the learning factors that causes postponement is the uncertainty regarding the time when the work should be started: that is, students are given too much freedom in choosing the time when they start working on a project.

There are many studies on procrastination, focusing on academic procrastination among others; mainly correlation studies. There were studies on procrastination correlation with gender [17] (no clear gender differences in the manifestation of procrastination were found), neuroticism and other personal traits [18], motivation [19], perfectionism [20]), anxiety [19; 21] etc.

There are three main areas of research on procrastination that can be distinguished depending on the study subject: analysis of situational factors (awards and punishments distribution across a timespan, level of unattractiveness of tasks), personality features (for example, fear of failure and loss of control over the situation) and individual features (gender, age) [22]. Thus, some authors [19] argue that procrastination causes anxiety, irritation, regret, and despair. It correlates with high levels of stress and inadequate coping strategies [23], which affects health and quality of life. In the studies of other authors [24], academic procrastination may have different impact on health and well-being of students, depending on the time when it develops. Typically, stress and the amount of pressing issues increase by the end of an academic semester. It was revealed in [25] that academic procrastination is most pronounced when performing routine homework assignments, in such forms of educational activity as writing essays and preparation for exams. Similar data were obtained in an earlier study [26]. The authors noted that students often postpone tasks that are highly complex, monotonous or uninteresting. At the same time, the results of other studies [27] indicate that students prone to procrastination deliberately avoid preparation for assignments, tests, or speeches. This is especially pronounced in situations that involve evaluation and any measurement of a person's abilities. Some authors [19] note that low motivation and interest, excessive self-confidence, laziness, lack of communication and consultations from teachers, are factors that cause academic procrastination. In addition, procrastination leads to a decrease in academic performance, an increase in the level of anxiety, often to the formation of an inferiority complex and, as a result, to discontinuing the study. The influence of the specifics of educational activities organisation on the performance of tasks should be noted. In the study [28], it is assumed that the longer the period is given for doing something, for example, exam preparation, the higher procrastination will occur. There is a study [20] on the links between procrastination and perfectionism. Thus, people with a high level of perfectionism tend to either perform the job well or postpone its implementation until they achieve a perfect result. Other studies $[1 ; 27 ; 29]$ reveal links between procrastination and low self-esteem, lack of self-confidence, poor selfcontrol, a high proneness to perfectionism, impulsivity, depression. In [30] it is noted that procrastinators to a much lesser degree focus on the future negative consequences of postponing planned tasks due to the desire to get short-term awards, as well as in an attempt to immediately overcome the sense of anxiety caused by a sense of insecurity regarding their abilities. Other authors [13] revealed that procrastinators are prone to absorption in memories of past achievements and successes, combined with the lack of attention to the plans for the future [31].

An analysis of the results of previous studies suggests that academic procrastination is associated with various personality traits and is widespread among students.

The purpose of the study: theoretical analysis of the procrastination phenomenon, as well as the empirical study on the links between academic procrastination and anxiety among students.

Research hypothesis: "There is a link between academic procrastination and anxiety among students".

\section{Materials and methods}

\section{Study participants}

The study involved $N=60$ participants aged 20-27 years. All participants were $2^{\text {nd }}$ year full time students of the Latvian University of Life Sciences and Technologies; 30 female aged 20-26 $(M=$ 21.97, $S D=1.79)$ and 30 male aged $20-27(M=22.90, S D=1.71) .50 \%$ of participants were not older than $M d n=22$ years old. 


\section{Methods of the study}

1. Procrastination Scale [1], in the adaptation of Bulina (2011). The scale measures the intensity of the procrastination indicator. The statements were evaluated on the Likert scale.

2. State-Trait Anxiety Inventory (Form Y) [32], in the adaptation of Skushkovnykova (2004). The questionnaire makes it possible to measure anxiety both as a personal feature, as well as a condition. The inventory includes 40 statements and consists of two parts. The first part measures situational anxiety, the second - personal. The statements were evaluated on the Likert scale.

\section{Results}

The obtained data were processed using the SPSS 20.0 software for Windows and MS Excel 2010. The reliability of the questionnaires was confirmed by the Alfa-Cronbach coefficient $(\alpha)$. For the Academic Procrastination Scale consisting of one scale including 20 items $\alpha=0.82$. For the StateTrait Anxiety Inventory, which includes two scales (personal and situational anxiety) of 20 items AlfaCronbach coefficient was in the range between $\alpha=.80$ to $\alpha=.84$.

To investigate the relationship between the variables, a correlation analysis was implemented using the Spearman correlation coefficient $\left(r_{s}\right)$. A link was found between academic procrastination and the scales of the State-Trait Anxiety Inventory. A positive statistically significant correlation was revealed between academic procrastination and personal anxiety $\left(r_{s}(60)=0.45, p<0.001\right)$ and situational anxiety $\left(r_{s}(60)=.42, p<0.001\right)$.

The frequency analysis was run to evaluate the statistical distribution of empirical data. The $\chi^{2}$ chi-squared test was used to analyse the differences in distributions. For this purpose, the indicators of academic procrastination, and situational and personal anxiety were divided into low, medium and high levels in accordance with the standards presented in the description of the tests [31]. The frequency diagram (Fig. 1) allows visualizing and comparing the distributions of the indicators. The $\chi 2$ chi-square test revealed statistically significant result (Fig.1) for the variables "Academic procrastination" - "Situational anxiety" $\chi 2(4, N=60)=11.71, p<0.05$. No significant differences in the distributions were found for the variables "Academic procrastination" - "Situational anxiety" $(n s)$.

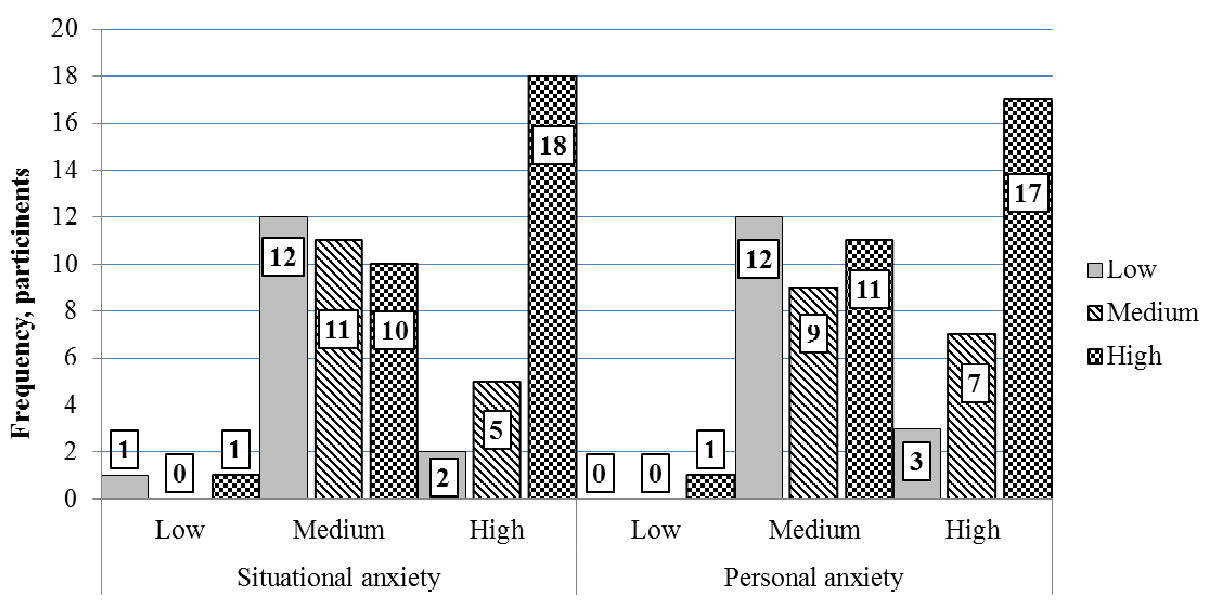

Fig. 1. Distribution of indicators of academic procrastination, depending on personality and situational anxiety levels

\section{Discussion}

As a result of the study, the hypothesis "There is a link between academic procrastination and anxiety among students" was confirmed. A positive correlation of academic procrastination with personal and situational anxiety was found, which is also confirmed by earlier studies $[19 ; 33]$ and the theoretical propositions that procrastination always leads to negative consequences, is accompanied by negative feelings and anxiety in the learning process. In the theoretical work [32], personal anxiety is described as a tendency to perceive situations as threatening, react to them with anxiety. Situational anxiety as a condition is characterized by subjectively experienced emotions - stress, anxiety, nervousness, inability to make a decision, etc. Usually, this state arises as an emotional reaction to a 
tense situation and can be of different intensity. For example, it can arise in a situation of uncertainty (waiting for a negative evaluation when passing an exam). The intensity of emotional reaction, generally, is disproportionately higher than the magnitude of objective "danger" [34].

There is evidence indicating that procrastination is one of the most significant factors causing problems in the academic process. According to [9], $80 \%$ to $95 \%$ of students in higher education institutions occasionally procrastinate, whilst about $75 \%$ of them consider themselves "chronic procrastinators," and almost $50 \%$ postpone important tasks systematically, causing problems. In addition, psychological studies show [35] that regular procrastination can be revealed in 15-25\% of the world's population. Moreover, the authors note that over the past 25 years, the level of procrastination has increased and is expected to expand further.

The results of the current study made it possible to identify the following tendencies: in this sample, students with a high level of procrastination (48\%) and the average levels of personality $(53 \%)$ and situational anxiety (55\%) prevail. It can be assumed that students with a high level of procrastination are more likely to experience anxiety, are more uncertain regarding the positive resolution of the situation, constantly delay the implementation of plans, start accomplishing tasks at the very last moment, when the deadline is approaching and it is nearly useless to try to catch up to the wasted time. Perhaps anxiety is aggravated by the high expectations of others as well as the excessively high standards regarding own work results on behalf of the student. As the results of a previous study [27] show, procrastination is especially manifested in situations, which imply any assessment and measurement of a person's abilities.

It can also be assumed that for students with a low level of procrastination the postponement of educational activities is not typical, thus, the problems arising from the untimely accomplishment of tasks are extremely rare.

In one of the researches [36], the authors attempted to reveal positive sides of procrastination by distinguishing passive and active procrastinators. In their study, they found that passive procrastinators postpone their tasks due to negative feelings (anxiety, indecision), whereas, active - delay assignments intentionally, i.e. they feel more comfortable when working within tight deadlines and under the pressure of being responsible for the results.

Procrastination is in some way typical for any age, but it has the greatest presence among students. Studenthood is an important period in a person's life. During this period, students make decisions regarding their professional choices and plan their future. Educational and professional achievements are very important; those lay the foundation for successful self-realization in the future. Therefore, academic procrastination is an important obstacle to these achievements, since the negative consequences of procrastination are expressed not only in the reduction of success and productivity in educational activities but also in acute emotional experiences of one's own failure, feelings of guilt, dissatisfaction with the results of their activities. The enhancement of abilities to set and maintain goal achievement, define priorities, evaluate the time boundaries can be recommended as a mean to reduce academic procrastination levels among students. For instance, organising educational seminars and training aimed at planning skills development within the educational process can help reduce the level of procrastination. The justified and balanced distribution of workload allowing decrease stress and anxiety can also be a method aimed at procrastination overcoming. Moreover, timely and systematic rest, maintaining environment optimal for learning activities can be effective methods of counteracting procrastination. Another learning factor causing delay can be uncertainty regarding the exact timing of work beginning. Thus, students can be given too much freedom in choosing the time. It can be assumed that reducing the time frame for writing any work or preparing for examinations can decrease the number of postponed tasks. As studies [25] show, academic procrastination is the most pronounced in such a form of educational activity as routine homework assignments. Therefore, there is a need to consider certain adjustments in a way how a teacher explains the tasks and teaching material overall and distributes the workload. A more careful attitude to teaching process, an encouraging and motivation system introduction, promoting academic ties among students, assignments division into smaller parts - all this can help to reduce the level of procrastination. Furthermore, at the same time, it is important to develop a sense of duty and responsibility among students, which will help to activate the teaching process. It is important to think about the methods of stimulation that can be used during sessions, when a natural fatigue arises and students need to relieve tension. There is a need to develop 
special training aimed at procrastination overcome and adequate planning skills acquisition essential for educational activities, as well as skills in prioritizing and time management.

\section{Conclusions}

1. Procrastination is a heterogeneous complex phenomenon, which includes behavioural, emotional and cognitive components, closely related to the motivational sphere of an individual.

2. Primarily, procrastination is manifested in behaviour: in the delay of required actions, postponing decision-making.

3. It is generally accepted that the educational process is characterized by the conditions, in which academic procrastination leading to negative consequences usually occurs.

4. The conducted research revealed the inclination to procrastination among students.

5. The positive correlations between academic procrastination and personal and situational anxiety among students were revealed. With the increase in the indicators of academic procrastination, there is a tendency to increased anxiety levels, which can result in academic performance decrease.

6. For this sample, the high level of academic procrastination and the average level of personal and situational anxiety are more typical.

7. Justified distribution of the workload associated with the educational process will help avoid the increase of academic procrastination and anxiety.

8. An important and promising direction in research on procrastination is the development of a program aimed at overcoming procrastination.

9. The issue of academic procrastination requires further in-depth studies to clarify and expand the existing data about the phenomenon.

\section{References}

[1] Lay C. At last, my research article on procrastination. Journal of Research in Personality, vol. 20, 1986, pp. 474-495.

[2] Burka J.; Yuen L. Procrastination: Why you do it, what to do about it. Cambridge: Da Capo, 1983. $336 \mathrm{p}$.

[3] Sabini J., Silver M. Moralities of Everyday Life. (Chapter 5, A plea for gossip). New York: Oxford University Press, 1982, pp. 89-106.

[4] Knaus B. The Procrastination Workbook: Your Personalized Program for Breaking Free from the Patterns That Hold You Back, 2002.

[5] Ferrari J.R., Johnson J.L., McCown W.G. (Eds.). Procrastination and task avoidance: Theory, research, and treatment. New York: Plenum, 1995. 268 p.

[6] Steel P. The Nature of Procrastination: A Meta-Analytic and Theoretical Review of Quintessential Self-Regulatory Failure. Psychological Bulletin, vol. 133(1), 2007, pp. 65-94.

[7] McCown W., Johnson J. Personality and chronic procrastination by university students during an academic examination period. Personality and Individual Differences, vol. 12(5), 1991, pp. 413-415.

[8] Solomon L.J., Rothblum E.D. Academic Procrastination: Frequency and Cognitive-Behavioral Correlates. Journal of Counseling Psychology, vol. 31(4), 1984, pp. 503-509.

[9] Ellis A., Knaus W.J. Overcoming procrastination. New York: Signet Books, 1977.

[10] Aitken M.E. A personality profile of the college student procrastinator. Doctoral dissertation, University of Pittsburgh. Dissertation Abstracts International, vol. 43, 1982, pp. 722-723.

[11]Eckert M., Ebert D.D., Lehr D., Sieland B., Berking M. (2016). Overcome Procrastination: Enhancing Emotion Regulation Skills Reduce Procrastination. Learning and Individual Differences, vol. 52, 2016, pp. 10-18.

[12] Effert B., Ferrari J. Decisional procrastination: Examining personality correlates. Journal of Social Behavior and Personality, vol. 4, 1989, pp. 151-156.

[13] Specter M.H., Ferrari J.R. Time orientations of procrastinators: Focusing on the past, present, or future? Journal of Social Behavior and Personality, vol. 15, 2000, pp. 197-202.

[14] Milgram N.A., Batori G., Mowrer D. Correlates of academic procrastination. Journal of School Psychology, vol. 31, 1993, pp. 487-500. 
[15] Solomon L.J., Rothblum E.D. Academic procrastination: Frequency and cognitive-behavioral correlates. Journal of Counseling Psychology, 31(4), 1984, pp. 503-509.

[16] Pychyl T.A., Coplan R.J., P.A.M. Reid Parenting and procrastination: Gender differences in the relations between procrastination, parenting style, and self-worth in early adolescence. Personality and Individual Differences, vol. 33, 2002, pp. 271-285.

[17]Lay C.H. Explaining lower-order traits through higher order factors: the case of trait procrastination, conscientiousness, and the specificity dilemma. European Journal of Personality, vol. 11, 1997, pp. 267-278.

[18] Haycock L., McCarthy P., Skay C. Procrastination in college students: The role of selfefficacy and anxiety. Journal of Counseling and Development, vol. 76(3), 1998, pp. 317-324.

[19] Çapan B.E. Relationship among perfectionism, academic procrastination and life satisfaction of university students. Procedia-Social and Behavioral Sciences, vol. 5, 2010, pp. 1665-1671.

[20] Sirois F.M., Pychyl T.A. Academic procrastination: Costs to health and well-being. Paper presented at the 110th Annual Convention of the American Psychological Association, 22-25 August, 2002, Chicago, Illinois.

[21]Chang H.K. Perfectionism, anxiety and academic procrastination: The role of intrinsic and extrinsic motivation in college students. Electronic Theses, Projects and Dissertations, 28, 2014. [online] [10.02.2018]. Available at: http://scholarworks.lib.csusb.edu/etd/28/.

[22] Tice D., Baumeister R. Longitudinal study of procrastination, performance, stress, and health: The costs and benefits of dawdling. Psychological Science, vol. 8, 1997, pp. 454-458.

[23] Tan C.X, Ang R.P., Klassen R.M., Lay S.Y., Wong I.Y.F., Huan V.S., Wan H.C. Correlates of Academic Procrastination and Students Grade Goals. Current Psychology, vol. 27( 2), 2008, pp. 135-144.

[24] Senecal C., Koestner R., Vallerand R.J. Selfregulation and academic procrastination. The Journal of Social Psychology, vol. 135, 1995, pp. 607-619.

[25]Ferrari J.R., Tice D.M. Procrastination as a self-handicap for men and women: A task-avoidance strategy in a laboratory setting. Journal of Research in Personality, vol. 34, 2000, pp. 73-83.

[26] Dolan P., Rudisill C. Babies in waiting: Why increasing the IVF (In Vitro Fertilisation) age cutoff might lead to fewer wanted pregnancies in the presence of procrastination. Health Policy, vol. 119(2), 2015, pp. 174-179.

[27]Ferrari J. Psychometric validation of two procrastination inventories for adults: Arousal and avoidance measures. Journal of Psychopathology and Behavioral Assessment, vol. 14, 1992, pp. 97-110.

[28] Baumeiseter R.F. Esteem threat, self-regulatory breakdown, and emotional distress as factors in self-defeating behavior. Review of General Psychology, vol. 1(2), 1997, pp. 145-174.

[29]Ferrari J.R., Díaz-Morales J.F. Procrastination: Different time orientations reflect different motives. Journal of Research in Personality, vol. 41, 2006, pp. 707-714.

[30] Scher S.J., Osterman N.M. Procrastination, conscientiousness, anxiety, and goals: Exploring the measurement and correlates of procrastination among school-aged children. Psychology in Schools, vol. 39(4), 2002, pp. 385-398.

[31] Kachgal M.M., Hansen L.S., Nutter K.J. Academic procrastination prevention/intervention: Strategies and recommendations. Journal of Developmental Education, vol. 25, 2001, pp. 14-24.

[32] Chu A.H.C., Choi J.N. Rethinking procrastination: Positive effects of «active» procrastination behavior on attitudes and performance. Journal of Social Psychology, vol. 14, 2005, pp. 245-264.

[33] Spielberger C.D. Manual for the state-trait anxiety inventory (Form Y) ("Self-evaluation questionnaire"). Palo Alto, CA: Consulting Psychologists Press, 1983.

[34] Spielberger C.D. Anxiety: Current trends in theory and research. New York: Academic Press, vol. 1, 1972, pp. 24-55.

[35] Wolters C.A. Understanding procrastination from a self-regulated learning perspective. Journal of Educational Psychology, vol. 95(1), 2003, pp. 179-187.

[36] Steel P. Arousal, Avoidant and Decisional Procrastinators: Do They Exist? Personality and Individual Differences, vol. 48, 2010, pp. 926-934. 